\title{
ORDERED SHAPES IN NONEQUILIBRIUM GROWTH
}

\author{
Eshel BEN-JACOB and Peter GARIK \\ Department of Physics, University of Michigan, Ann Arbor, MI 48 109, US.4 \\ and School of Physics and .Astronomy, Tel Aviv University, $69978 \mathrm{Tel}$ Aviv, Israel
}

\begin{abstract}
Patterns observed during nonequilıbrium growth display complex ordering on many length scales. We focus on ordered patterns which reffect the interplay of microsce: $r$ and macroscopic dynamics. The fundamental morphologies which result, and which are the building blocks of more complex patterns, include dendritic and tup-splitting growth. The latter gives rise to the twodimensional dense-br. "Ir" wh . . orphology (DBM). We review the current understanding of how dendritic growth and the DBM anse from the microscopic dynamics of surface tensıon and surface kinetics. We emphasize the open questions, with particular attention to the question of developing theory 'or morphology selection and transitions between dendritic and dense-branching growth. In this context, we review our hypotheses of the selection of the fastest growing morphology, and the existence of firstand second-order-like morpmology transitions. Theoretical sssues are illustrated using the Hele-Shaw and electrodeposition expernments.
\end{abstract}

\section{Introduction}

We are surrounded by a nature our of equilibrium. a nature which presents the scientist with a bewildering and mesmerizing !niverse of patterns. A principui challenge to physicists is to understand the geometry of ihese nunequilibrium paters. wheiher :he) aryse as ohysical objecis - mouniains. snowrlakes, dust motes - or as mathematical abstractions, e.g. time correlations, or density fluctuations. The quantification of the geometrical properties of these nonequilibrium systems, and our understanding of the dynamics which gives rise to these geometries, has made large gains over the past decade. In large part this has followed from a recognition that nature supercedes Eucind's Elemenis. and that much of her Wutterning is best understood with the "fractal" geometry dessribed by Mandelbroi [1].

Concurent with the sciartife communin's recog. riton tha neture is not restricted to paterss of EnEudean jumerision, these pasi fiew years have sen the det elooment of a new understanding of specific pai ien: lhal recur during nonequilibritm growh". These paitarns, the dendrite and lip-splining "fingering" growis appear on system-derendent langth

Esisjoun ponour ol genoug Mardolbrot

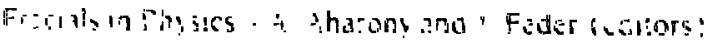

scales varying by many orders of magnitude. In effect, they are the short-length-scale building block morphologies from which are composed the more complex patterns visible on iarger length scales. While the larger paiterns which develop during solidificaiion, aggregation. or condensation still require new insights to explain the global morphology assumblage, significant progress has been made in understanding the determinung physics of dendritic and tipsplitting growth, and their interrelationship as fundamental morphologies.

The comerstone of the recent developments is the rezognition of the interplay of microscopic interfacial dynamics with external macroscopic forces in the determination of growth patterns. Most of the research has focused on systems where the macroscupic dyaamics are determined by a diffusion field. We now understand than for these sys!ems, the pattems that form. result from competition between the

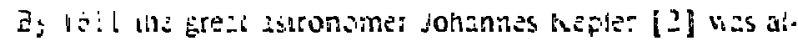
ready captivated b' the beautivil shapes of snowntakes, which 15 perhaps the most strikung examfle oi pattern formarion in morgarii systems See also rci. 131. For a review of the preyous phase of the rescarch on patterr formatu on dunng solsM

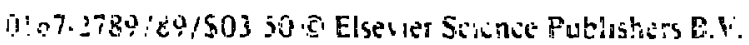
iNorh-Holla.ud Ph, sice Fubluhune Cinision!
} 
diffusion field on the one hand. and the microscopic dy namics of the interface on the other. The patterns may be grouped into a small number of typical "essential shapes" or morphologies, observed in dithereni systems and over many different length scales (from meters to micrometers). These are the faceted [5]. dendritic [4], dense-branching [6] and fractal [7.8] morphologies (see fig. 1 ). It is the purpose of this short review to provide a perspective on the advances in the field of morphology selection with an emphasis on general principles and the remaining open questions.

\section{The selection problem for dendritic growth}

The principal mystery in how microscopic dynamics, operative on the scale of angstroms. is amplified to the extent that in a system out of equilibrium it controls the macroscopic shape on a scale of centimeters. From a theoretical perspective herein lies the rub. The natural inclination is to atiempt theortes of growih emphasizing maciuscopic dynamics and relegate the microscopic dynamics to subsequent refinements of theory. Indeed this was how the theor of dendritic growth initially evolı ed. In 1947 I tantsos showed [10] that propagaing solutions. whth a parabolic shape. evisi for a solid forming frumi an under cooled meli by assuming only diffusion control of the heat field but neglecting surface tenston and surface kithellics. Both the parabolic shape and the predicted constant velocity fit well a semi-quantitative description ol a dendrite. However, a conundrum comes with the Ivan sov solution: it specifies only the produri of the dendrile sup's radius of curv ature and velocil. , but sannot predict either one alone. The 1976 espertmenis of rilicksman al al. [11] demenstrated that under conirolled conditions, ior gan andoramilig the same dendrate li.e. same lip relocin and radius

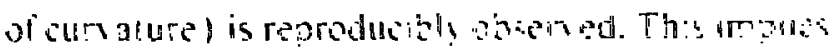
a "selection problem": for gu'er undercooling the

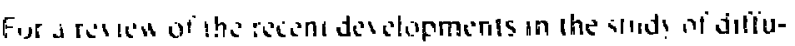

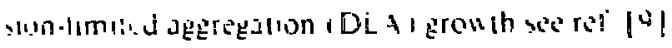

Ivanisor solution admits a contınuous family of parabolic solutions. and yet for specitied condutions only one is observed. Moreover. it was shown that lints Irantsor solutions were also 'incarly unstios. . meaning that they would be unable to maintain their shape during growth.

Sensibly the first attempts to resolve the stability problems were based on a hope that incorporation of surface tension would involve only a minor shape modification of Ivantsov's parabolic fronts. while stabilizing all parabolas below a characteristic length scale. However. the selection problem remained inherent in this. In 1973 Oldfield [12] proposed that the selected dendrite was the one moving with the minimı'm speed for maximum radius of tip/ for which the surface tension san stabilize the underlying needle-crystal. Oldfield's idea was revived and elaborated in 1977 by Langer and Müller-Krumbhaar [13]. who performed extensive calculations in order to find this marginally stable operating point.

The real breakihroughs in understanding dendritc growth waited until this decade. and arriled with results of bronder signilicance for morpholog! deier-

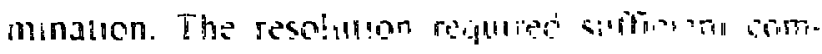
putung power and lie subsequent apphicaicu of mors advanced math:matea! melinds :o provert now-

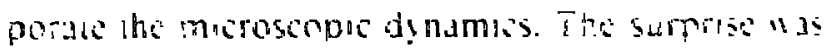

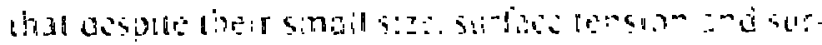
lace kinetics are singular perturbations in the d! namscal equations for interface evolution. Singular perturbations. no matier how small. totally change the character of the solution. As stuch. the microsiopic d! namics cannot be treated as smail correstons 0 solutions unulualy, delermilsed from the macruscopic difnamios. 4 hat has emerged is that when surface fension and surbes hineliss are solropic dendrid:

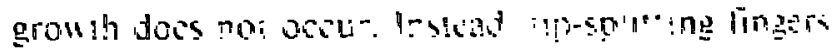

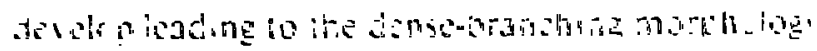

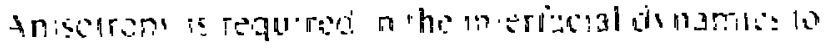
rotatedand

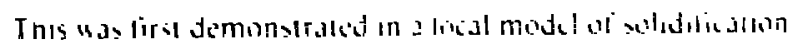
- the boundar! later model [i+1
} 



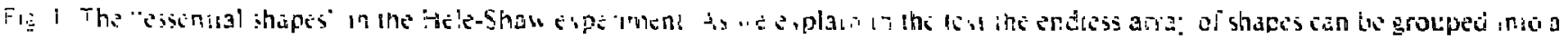

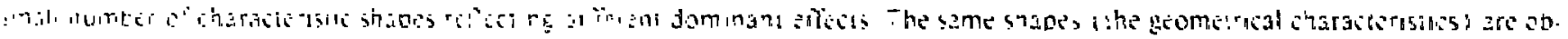
sened in dulierend systems and on duterent length scalis (from meters to micrometers). (a)The dense branching morpholog!. The

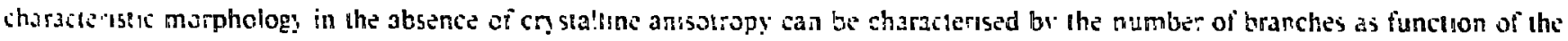

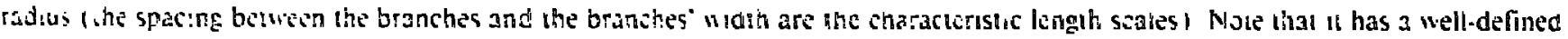

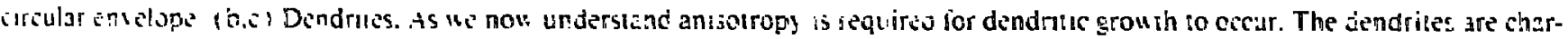

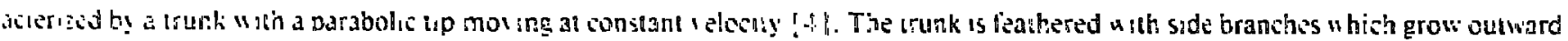

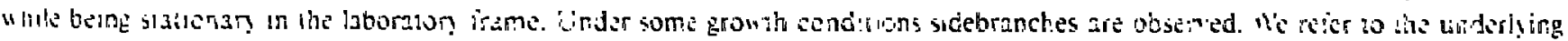

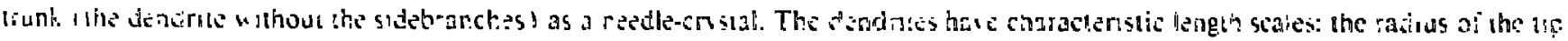

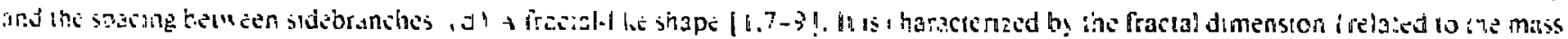

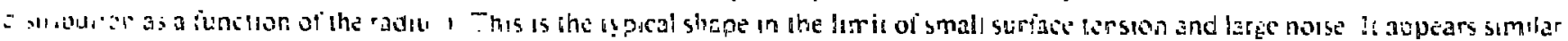

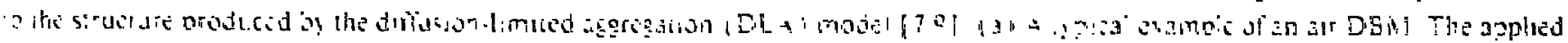

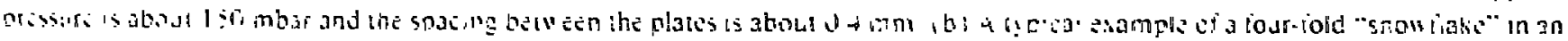

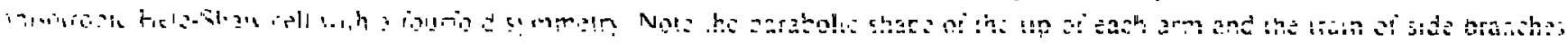

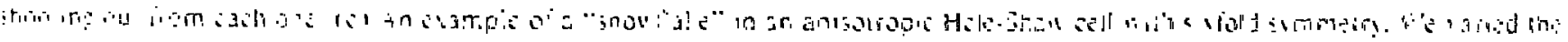

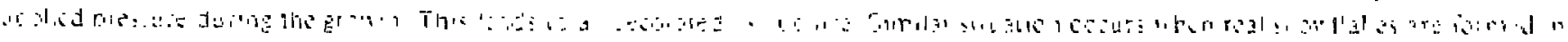

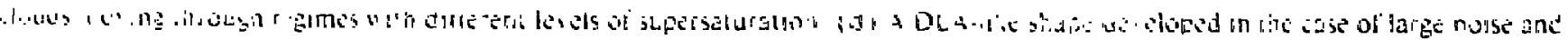

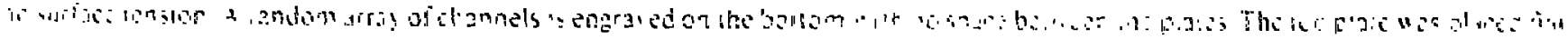

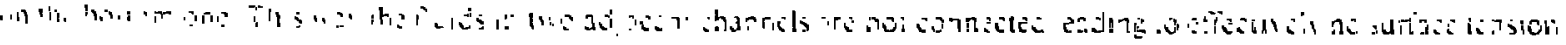


firmed by both experimental [ 15.16 ] and theoreicad resulis $[14,17]^{\text {at }}$.

Nen select:on problems emerged with the breace: understanding of pattern deverminarion. The puzzhe is no longer the dendrite's velocity and shape alone. Now the questions are as to why dendrites are seLited for some parametcrs, and tip-splitting growth for others. To study these new selection problems we turn to an experiment in which the interfacial dynamics is expressed on the same length scale as the pattern [15.19.20]. These experiments, d:scussed below. permit unambiguous demonstration of morpholegy selaction as a function of anisotropy.

\section{The dense-branching morphology}

To study pattern formation for isotropic interfacial dynamics. we used a modification of the Hele-Shan cell " . This simple. yet elegant, device for cudying pattern formation consists of two closely spaced plexiglass plates sandwiching a layer of visccus thas - here dyed glycerine. The icp pute is cicular and

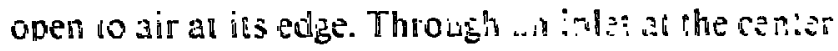
of the top olate a less r iscous Mud is g. ai: or arer h is injecled into ine gly cerine.

In fig. In ar example of tho dense-brahtine mar-

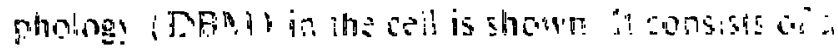

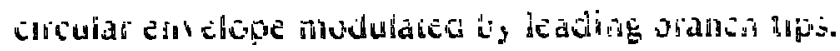
The ragilar tho-spliting of the fingers distinguishes them from dendrias. Morevrer the lacunae or gams keiwe sn the firgers do not grow with the area of displaced fuid. This dinnguishes the mass dictrikution of the DERi from that of a fizal abjecl. such as a

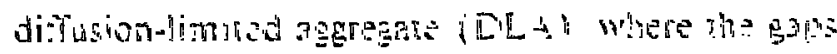

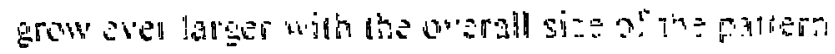

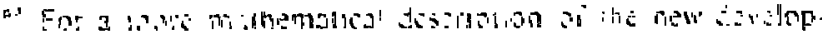

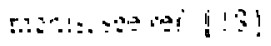

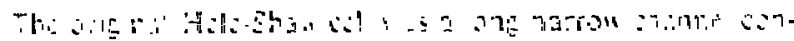

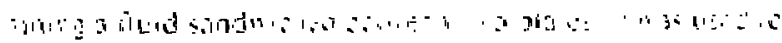

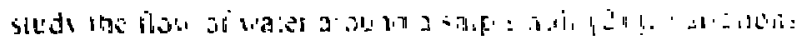

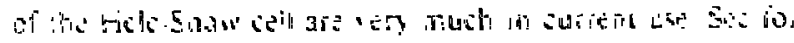

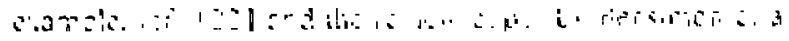

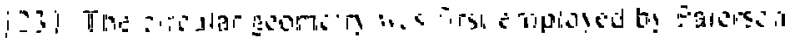
$12 !$
}

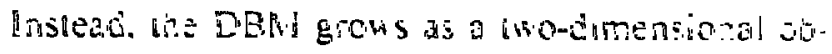

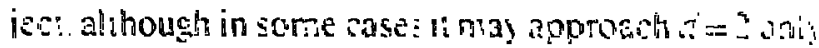

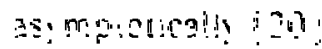

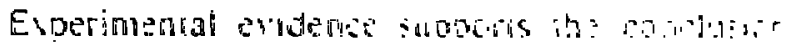
that in the absence of anisotropy. the DBM is the generic morphology $[0,20]$. This is contrary to the argument that fractal growth should be the usual macroscopic morphological organization $[25]$ the DBN is observed in aggregate growh by electrochemical deposition " and precupilation from suprsaturated solution [29]: during solidification i z aij undercoooled melts $[30]^{\text {"x: }}$ : arising during arisuphous annealing [6]: and in spherulitic growih [31].

Our present understanding of the DBN1 is based on analyzing its branching rate. as opposed to tis mass distribution or coastline. Generally. We expect ine branching rate. or surface modulation. so be the result of the interplay between the macroscopic diffusion field, which tends 10 make the interface irregular, and the microscopic effecis of suriace tension and

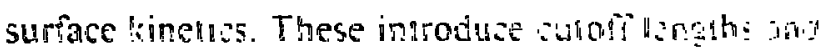
define the length scale of ordered scow th Tumbing

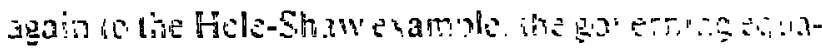

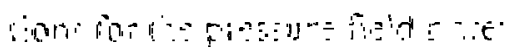

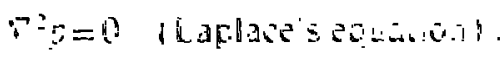

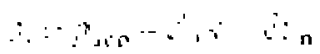

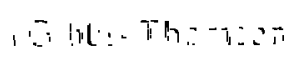

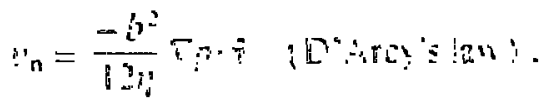

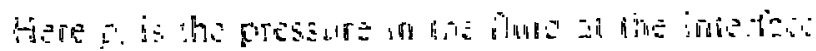

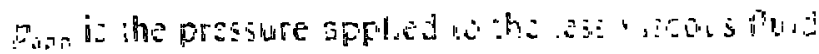

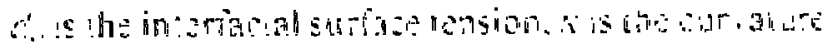

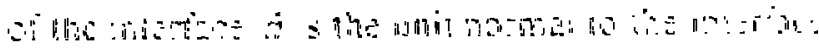

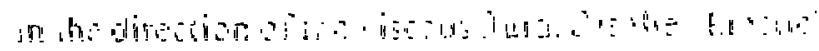

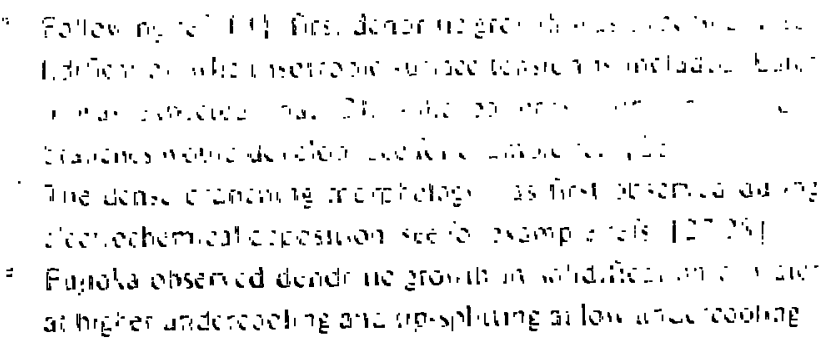


coefticient. $b$ is the spacing between the plates, and $\eta$ is the fluid viscosity. The exponent $\mathrm{l}$ ' has been compuicú ds i for a uñifúrin weiiina layer. would be different for a non-New :on an fluid. and is raken as unity in our simple analysis below. Although the differential equation for the pressure field here is Laplace's, the physics of these equations is nearly isomorphic to problems where the governing equation is strictly the diffusion equation. e.g., precipitation from supersaturated solution, or solidification from an undercooled melt.

Linear stability analysis [32] ".- san be used to insestigate the branching rate of the DBM. Indeed. the instability of a diffusion-controlled interface to any perturbation in the absence of a Gibbs-Thomson-like stabilization. is the Mullins-Sekerka instability. Using the above equations. we can compute the relative growth rate of perturbations on a disk of radius $R$. Taking the perturbation to be of the form $r(\theta)=$ $R+\delta_{m} \cos (m \theta)$ for small $\delta$ we find that:

$$
\begin{aligned}
& a_{n,}(x) \equiv \frac{\dot{\delta}_{\ldots !} ! \delta_{\ldots, n}}{\dot{R} / R} \\
& =-1+m\left(x+\bar{\beta}-\frac{\left(m^{2}-1\right)\left(x^{2}-x^{-1}+\bar{\beta}\right)}{5-1}\right) \\
& {\left[n: \bar{B}+1\left(\frac{1-1}{1+1} \frac{1}{1 \cdots}\right)\right]^{-1} .}
\end{aligned}
$$

where

$\xi=\frac{p_{s}-p_{i 1}}{d_{11} / p_{i 1}}$

$\bar{p}=\not B h \because 12 \eta R_{n}$.

and

$x=R i R_{1}$.

$R_{11}$ the cell radius. Fig. 2 show s that there's a lastest growng Feriutahom Eiperimentaily. gcod agree-

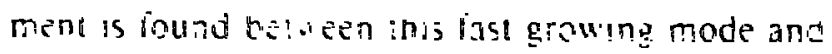

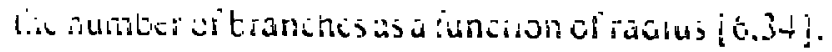
This anal!sis is consistent with the DLA-like dimen-

4. umilar linear analy sisto that presemled here u as peiformicil independeill: b! Schusne [33]
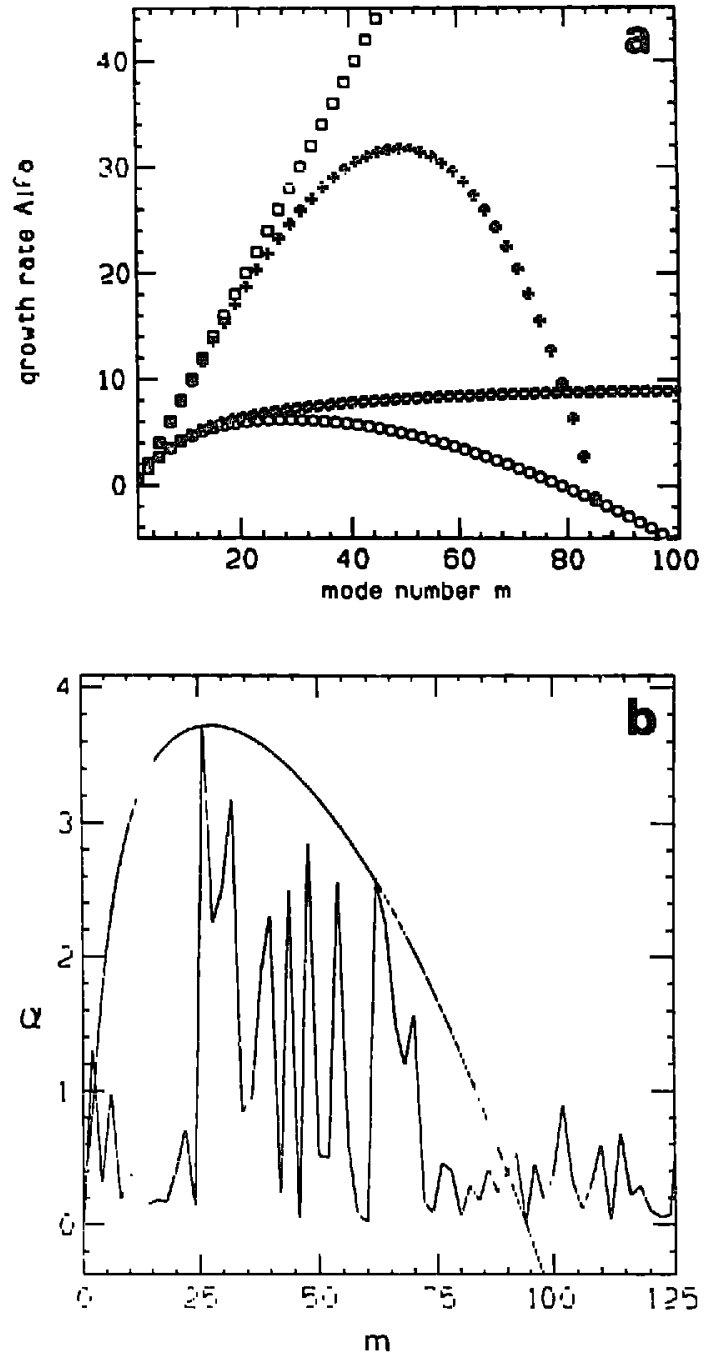

Fig. 2 The DBM and the linear stability analysis (a) Results of the linaar stabilı! analysis, shou ing the initıl growth rate as funciun of the mode number in for a sinusoidal periurbation d of a circular interiace Line $(1)$ is for constant pressure along the interiace i no surface tension and no suriace kinelic I. IIne $(2)$ is when surface tension is included and line $(3)$ is in the presencs oi surface hinetics Note that in the latler case there is no fastest growing mode. Line ( + ) is in the presence of both surtiace lension and surface kinetic. $(b)$ shous a comparison of the linear stabilit) and an espenmental fou er specirum of the en elope of a DBM

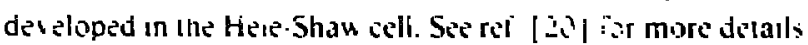

sıon of mass of sma!l Heie-Shaw pa:terns: howerer.

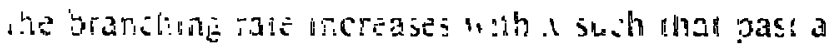
critical value. determined by system parameters. the growth is $d=2$ as observed $\checkmark$ isuall! [20].

in the absence of siabulizing eflects at the interface. "wich as surface tension or surface kineuics. the difiu- 
sive Mullins-Sekerka instability results in an unstable interface. The result is noisy. apparently iractal. grow th. This is what happens in the modelling of growth by the DLA algorithm [7.9]. where there is no surface tension. This is also the case when two miscible fluids are used [35]. or glass beads are added [36], in fluid flow experiments. In both of these cases the net result is to reduce the interfacial stabilization effect of surface tension.

The nature of the envelope of the DBM is an integral part of the dynamics of the pattern but its understanding requires a nonlinear analysis $\approx 10$. A naive understanding is that if one finger outgrows the others, it has more space to spread out; part of the flow goes sideways and the finger flattens and slows down. In our view. the mosi pressing unsolved problem is to understand the branching rates and velocity of DBM growth [19.31]. The latter is especially intriguing because there may be a selection mechanism operating with respect to the branching rate and interfacial velocity akin to the tip-radius and velocity of the dendrite selection problem [38].

\section{Dendritic grom th and morphology diagram in the anisotropic Hele-Shau cell}

The Hele-Shaw cell can also be used la shuil anisotropic growth. analogous to the solidification of a crystalline material. There is a strikingly simple way to mimic crystalline anisotropy in the fluid cell: one engraves channels on one of the plates. The channels modulate the spacing between the plates $s 2$ as to create deep and shallow paths for the flow of fluid. When the grooved lattice has six-fold symmetry tihree sets of parallel channels oriented at 120 : 10 each other 1 . the air bubble adopts beautitul snowhake-file shape; wh sis dendritic arms. Smce snowiall on Niars is comnosed aico. makes with fouriblat anisorropy. a

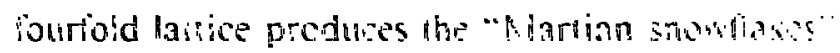

\footnotetext{
"... [n rel. [ 37 | It is claimed that the circularnit of the enselope in

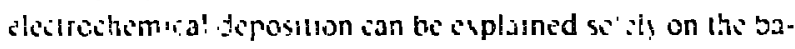
sis of linrar slabilit onalysis $M$ en the aggregate has a finite resısıIII.
}

of lig. lb. The emergence of dendrites in the HeleShaw cell [ ! 5$]$ prou ided the first direct esperimental demonstration that anisolrop! is needed ier denditlic grow th to occur.

But not only dendritic growth is observed in the presence of anisotropy. As we vary the applied nressure (the driving force) the air bubble assumes different shapes. Similarly, different morphologies are observed as the "microscopıc" growth conditions are changed. For example, we can change the level of anisotropy simply by changing the spacing between the plates. The idea of a "morphology diagram" to organize the observations follows naturally [ 19. 20].

Fig. 3 depicts a morphology diagram for a cell with sixfold anisotropy. Faceted growth, the DBM. and wo t!pes of dendrites now occur, for different values of the applied pressure. As we will see later on, the existence of two types of dendrites play an important role in our understanding of morphology ransitions. A morphology diagram is also observed in electrochemical depositıon experiments [27.28]. Hele-Shan cells usıng lıquid crystals as the viscous huid [16]. and solidification from supersaturated sol ': $3 n 5[30]$.

Se. eral quesions arise now: why dow wnisosroy" trigger dendritic grow $2 h$. and if 1 t does. "hy is the DBM stll ous.r es: li'h so some dendrues arpez:

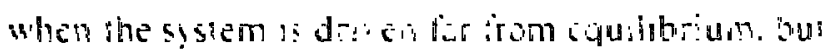

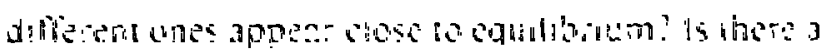
general selection principle that will delermine which growh will be observed for specifted conditions. leading to a theoretical understanding of morpholog: diagrams?

\section{Amisarrany and ithe for mation at deandrites}

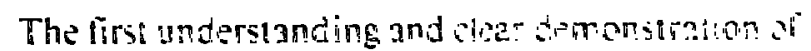

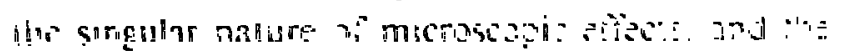

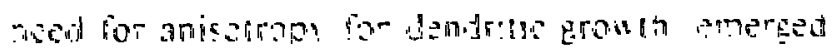
Fo grow th [ ]2.17]. The immedate goal in the construcllon of diese models wa yo pirpornt the prysical etrects that were essenial ior dindric gionth. Earite: altempis without ihe drastlc simplifications of the lo- 

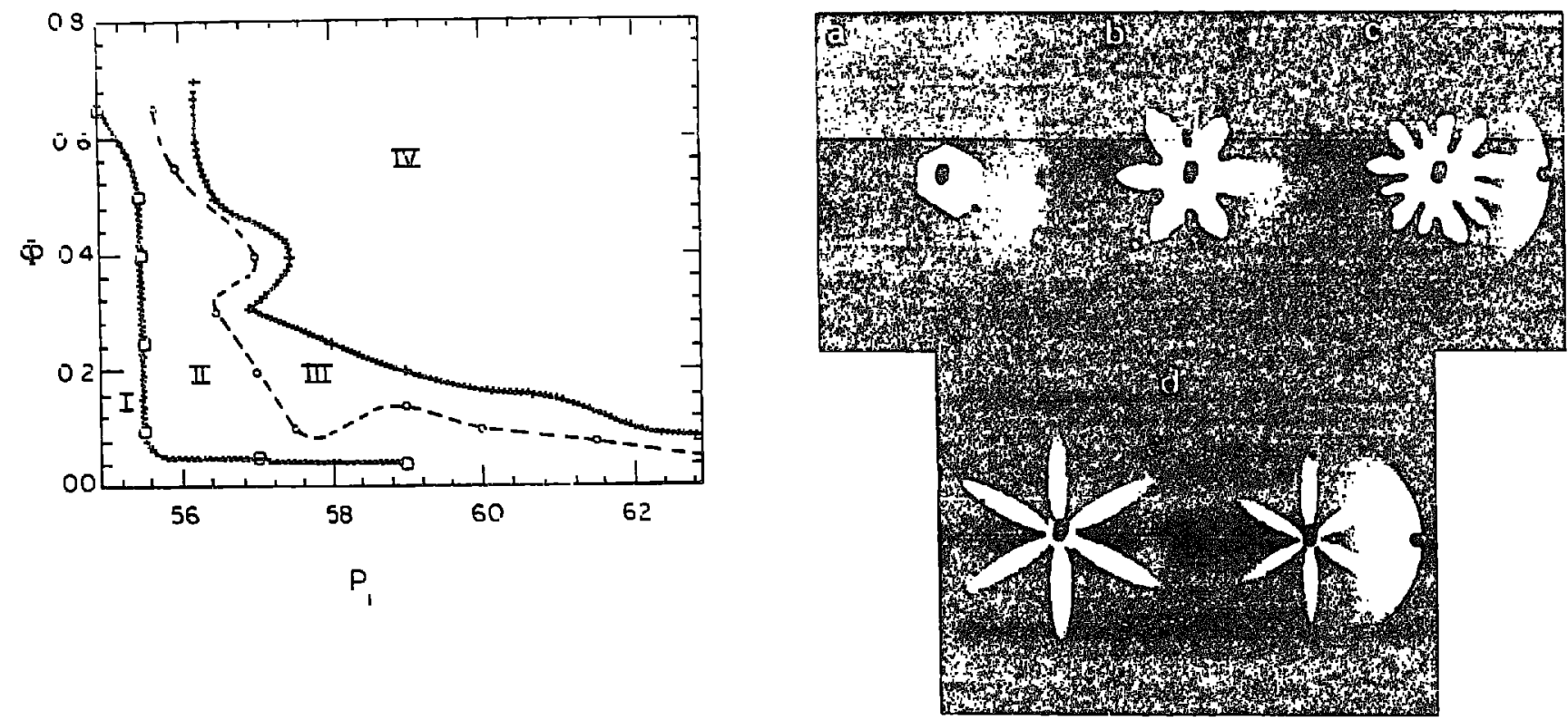

Fig 3 Morphology diagram ior a sixfold anisotropic Hele-Shau cell (the cell is the same as described in refs. [15.19].) Here $P_{1}$ is the applied pressure measured roughly in cenumeters of $\mathrm{Hg}$ (the actual manometcr fluid was a light oll). The anisotropy of the cell is measured bs the ratio $\Phi=b_{1} i\left(b_{c}+b_{1}\right)$. where $h_{1}$ is the depth of the grooves $(0.015$ in $)$ and $h_{n}$ is the additional spacing between the top plate and the top of the grooved plate. The morphology regions are 11 ) faceted grouth: (II) surface-tension dendnic growth (uith iarci"' :nsoection it is possible 10 obserne that the dendrites pount at an angle of 30 : to the rulung of the grooves:; illl! tip spliting



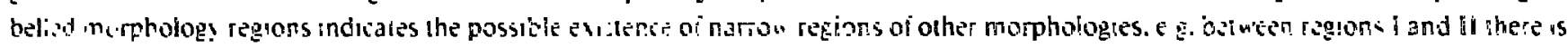

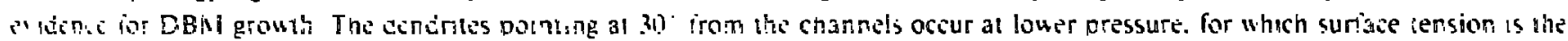

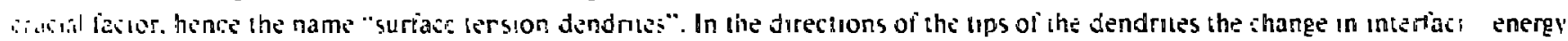

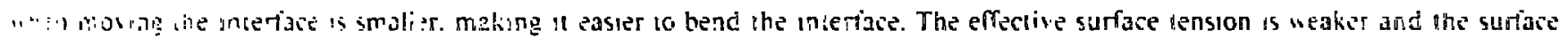

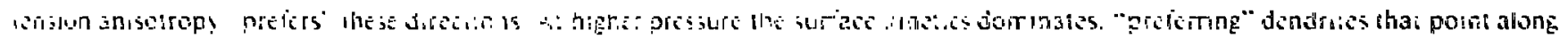

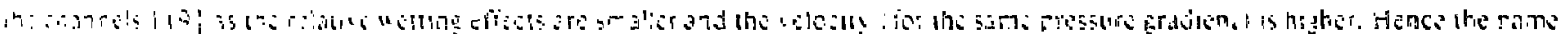

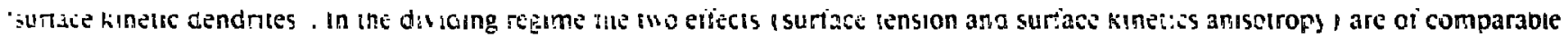

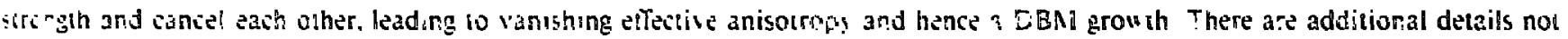

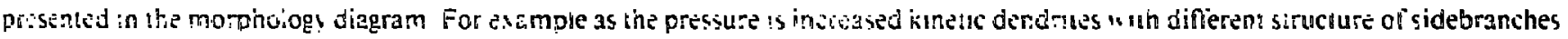
are obsenes. Oniv the rain fealures of the matghology diagram are presented here ial-id) are iaceled. surtace tension dendriles.

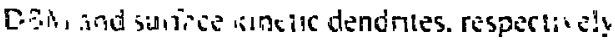

cal recels had failed because of ho dihiculti ojschreg an numascalts the full ditusion problem. in the local models. the interface is treated as a dynam.

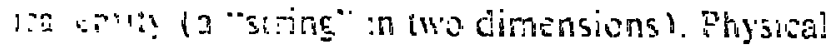

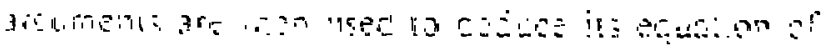

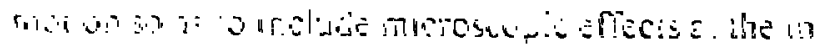

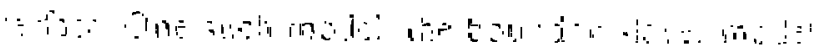
1Ethli "us inspire' by solidthation from an an.

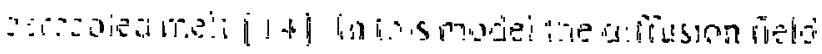

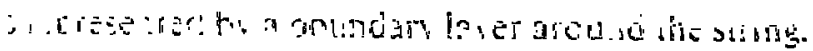

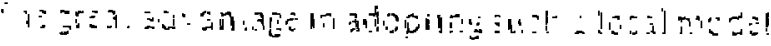

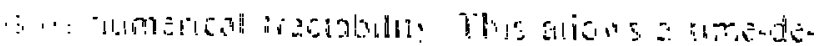

CEncunt solwton or the computer explicity snowing the incriacia? eviution. In this way' it was tirst recconied that in the sbsence of anisotrcp: lipesplitting

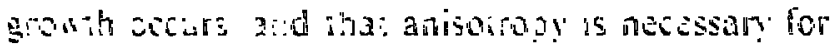

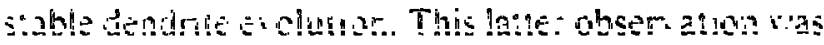

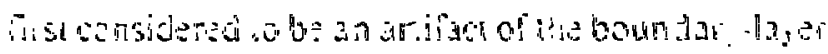

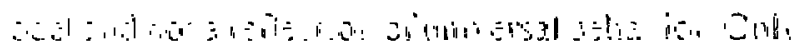
after the demonsteanco o the anisouropic Hele-Shaw

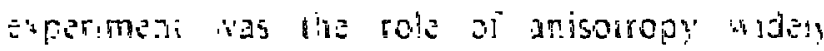

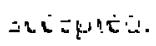

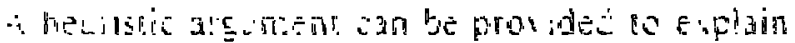

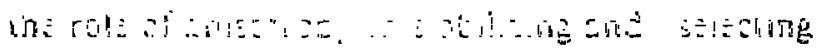


the dendrite's tip. Consider a parabola of the form $y=-a x^{2}$. Let $\theta$ be the angle between a suriace normal and the 1 -axis direcuon. The simplest "ay 10 introduce anisotropy is in the surface tension $d(\theta)$ where the angular dependence is presumed to arise from variations of surface tension with different crystallographic orientations. Explicitly we write the Gibbs-Thomson relationship relating the surface iemperature $T_{5}$ and the melting temperature $T_{n}$ :

$T_{\mathrm{s}}=T_{\mathrm{M}}-d(\theta) \kappa$

and

$d(\theta)=d_{10}\left[1-d_{1} \cos (6 \theta)\right]$

for the case of sixfold symmetry. First consider the case of no anisotrnpy. $d_{1}=0$. Then the tip. $\theta=0$, is the coldest point on the interface. As such tl experiences the maximum temperature gradient and is the fastest growing point on the interface. The dynamic response of the system to this circumstance must be dimusion of hea: along the intertace low ard the lip. This will cause the inp to slow down. we further reason that symmetrically placed gois? is ca! s. elog at. the miertace "hich grow more rapidly ihan the lip.

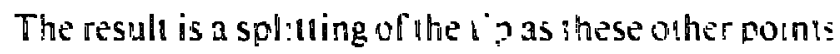

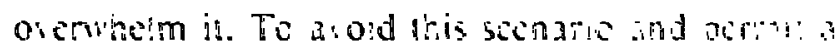

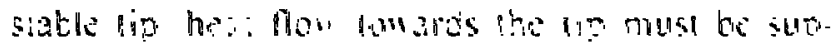
pressed. This is enacily the effect provided by ons-

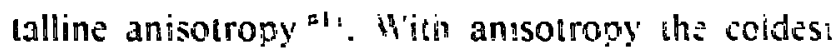
paini moves ar.ay from the lip an a poun whis a difEerent growth direction. For large enough anisotrop:

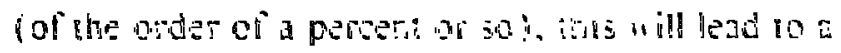
ather sults inerelay of the anisctropy and the possible neadle ch sial. Fo a given anisurops on't tha needle-sryslal whth the right lip lalocily ano up our-

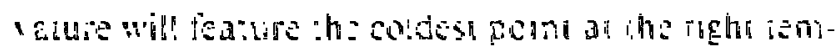

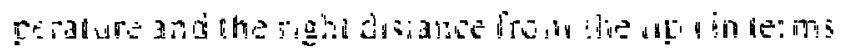

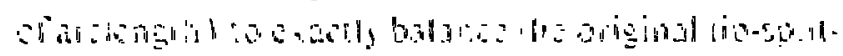
19.

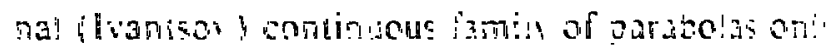

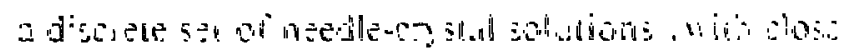

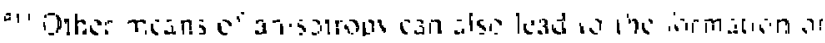

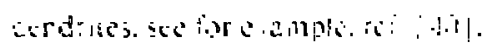

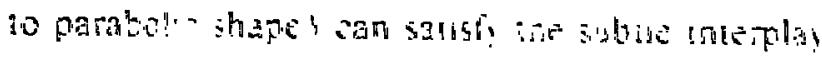

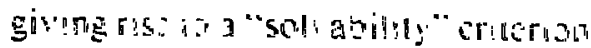

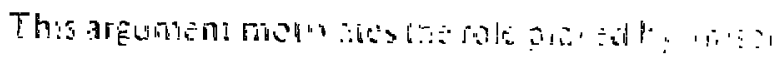
ropy in the existence of stable steady-state needlecrystal-like solutions. But. how does this lead to dendrixic groitis composed of a needle-crysial n runk decorated wish slde-branches, and the selection of a specific dendme? If we pertarb the needle-cry'stals. say by introdusng a bulge near the tip. the periurbation will grow siording to the diffusite instability referred to atsic. The bulge will grow outward at a fixed position in space. so as the up advances, the perturbation mot zs backward if iewed from the tip. It can be umagirea shat only for the fasiesi nedje-crsial will the butse move backward faster than lis growih rate. allowing the tip to restore its shape despite the growing perturbation. This mechanısm results in decorating the fasiest needie-crstal with sido branches. and turning it into the observed dendrite. the only one thot can exist.

The nunerucal iarnulation of his "macrosiopiz

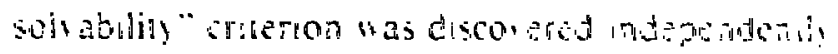

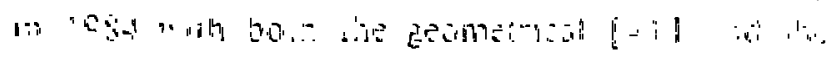

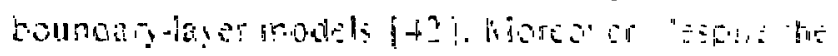
hand a a : and b.6.

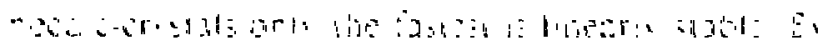
now l! is insw yha: the same mechan ism ys presconll

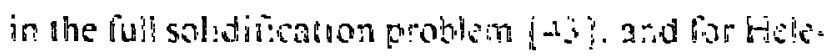
Shan in chasnel geomeary. Tins latler a knuwn as the Saftimen-Tay lor probem wibh the chantal wall frow

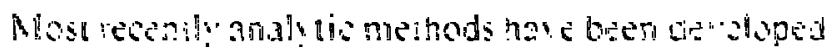

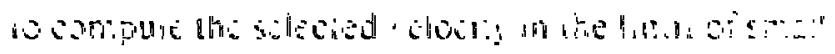

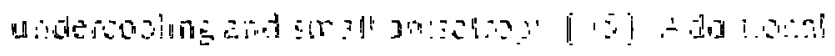

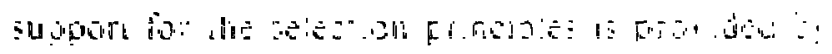

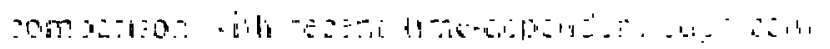
ond

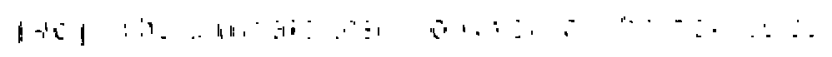

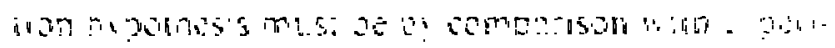

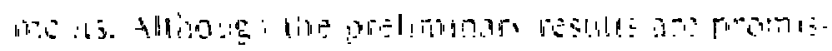

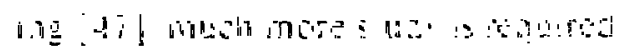

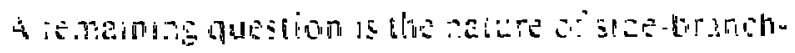

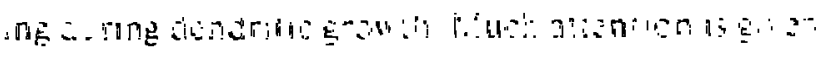


to this question now [48], with the debate focusing on the relative role of noise as opposed to deterministic dy namics in the growth of side branches. Either they emerge as a result of noise that excites the diffusive instability and linear stability is sufficient to predict their evolution, or an additional solvability principle is required. We believe the latter to be the case: however, we must leave this topic outside the scope of the present article.

\section{The ' lastest growing morphology" selection hypothesis and the morphology diagram}

Despite the discovery of the microscopic solvabillty criterion. the problem of dendritic growth is not fully resolved [49]. Time-evolution studies of the interface in the boundary-layer model. and the anisotropic Hele-Shaw experiment. present a nagging problem. Both show that even with anisotropy present. dendrites are no: always observec. As we decrease the driving force (pressure in the Hele-Shaw cell and undercooling in the BLMI) there is a critical value below which dendrilic growth is no longer observed, Instead tip-splitting ( the DSN1) occurs. Simnar behas ior is also obser ed durng treazing of u aler [30]. These resulis contradtet the selection principi: for dendritic growth. which suggests inat as long as anisotropy is present, a specific dendrite (corresponding io the fastesi needle-crystal) can exist and is linearly' stable. The observation of the DBMI under growth conditions suitable for dendrites as well means that with present theory the iwo morphologies can coevist. "Nicroscopic solvability " can clearly be only part of the picture. A more general principle is needed io disinguish bemeen different morphologies and determine the one which is selected.

"ye ha a proposed [ 14 ] the more general puncuple

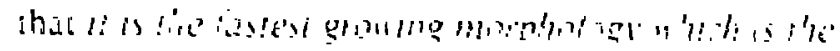

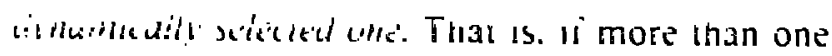
morpholog! is possible. onl: the fastest one is nonimearly slable and utll be obsened. Thus. one might nfer that below sorre calleal dis ing force the wor-

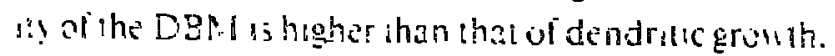

and so the former is selected. Motivated by our HeleShaw experiment we have also studied the case of competing anisotropies. Both surface tension and surface kınetıc anisotropies are included and they have preferred growth directions offset by $30^{\circ}$ as in the sixfold Hele-Shaw cell. We calculated the selected velocity both along the surface tension and the surface kinetic directions. The results (fig. 4 ) show that above a critical undercooling $\mathbb{d}_{\mathrm{c}}$ both types of dendrites are possible, with the surface kinetic ones having the higher velocity. Time-dependent simulations of the BLM demonstrate that indeed the surface kinetic dendrites are the dynamically selected morphology in this regime.

Let us explore furher the analogy between phase and morphology diagrams. For phases in equilibrium. for a given set of conditions the phase that minimizes the free energ.' is the selected one, independent of the prior history of the system: the concepts of a selection prirciple and a phase diagram go hand in hand. In contrast. nonequilibrium growth processes are tıme dependent. so it is not clear a priorı that a morphology diagram st.ould cxist ( that is, that the shape will depend only upon the growth conditoons and not on the history 1. However, if it does ex:1. a selection principle musl evist if a given moroholog: is reproducible for a glien sel of growth condıuons. Given such a morphology selection principle, It is possible to generate a map of what shapes should be observed for what growth conditions. The existence of a morphology diagram has been confirmed experimentaily in various sy stems, suggesting that a selection principle must evist. Is this principle the "fastest grow ing morphology" hypothesis that we have proposed? We believ'e that the latter is not the most general pronciple lie saek, but is a step $n$ the righi direcition.

When a system is druen out of equilibrium by the impostuon of a gradient in one of the hermodsnamic barables fe.g. the temperature or the concen iration: the response oi the system is described by the conjugate this lthe heas 17 s and particle tlux, respecuely. These huses ma! in general be viewed as he rite co entropl protichom or the rate of ap- 

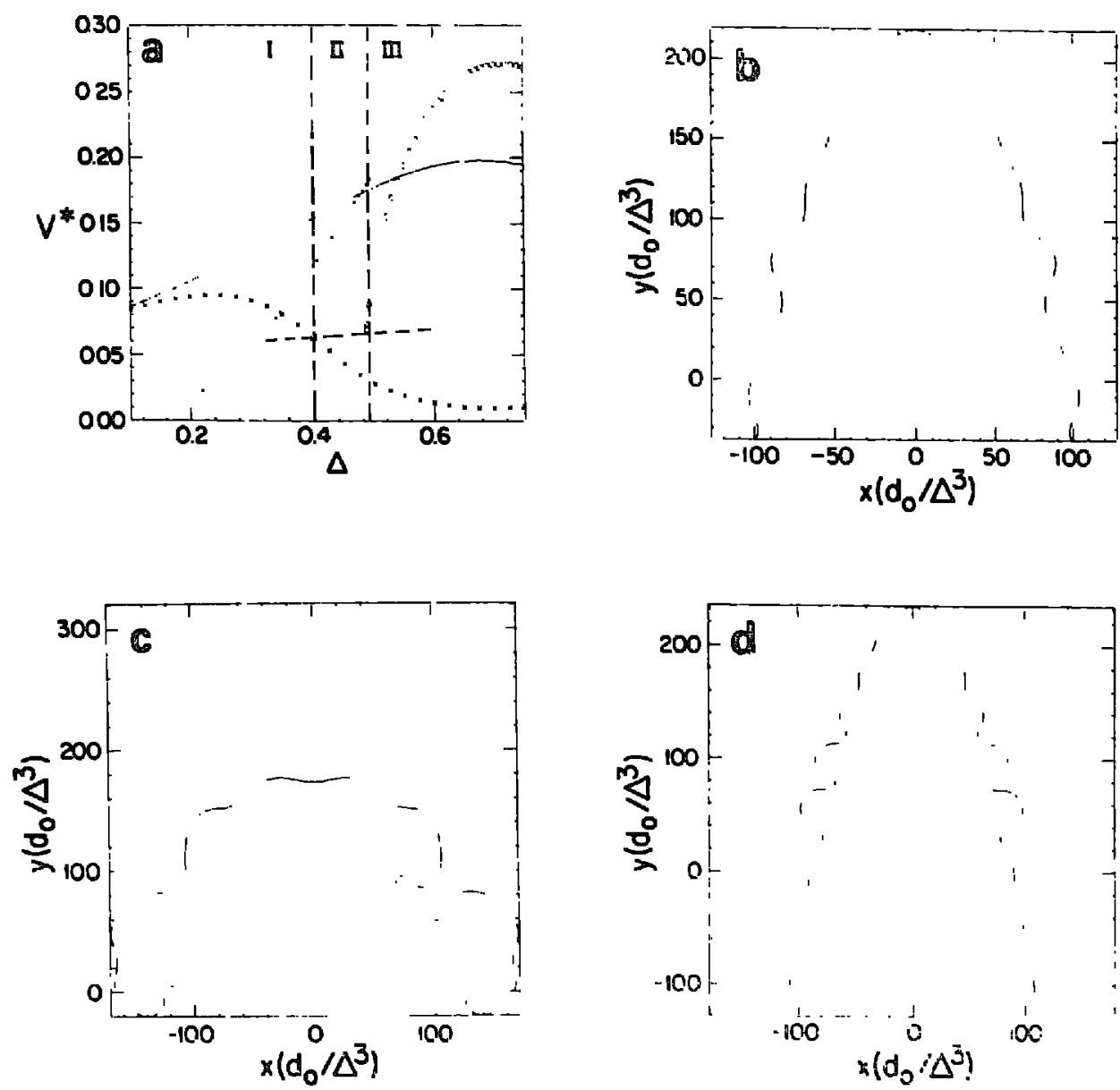

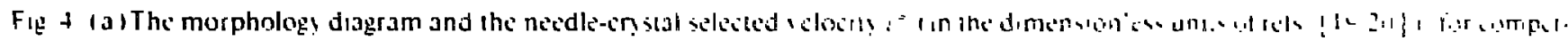

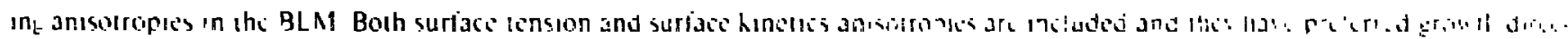

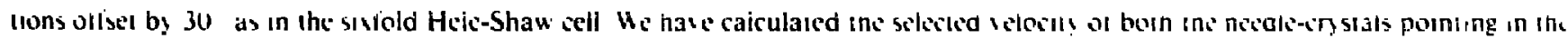

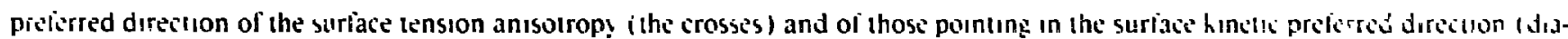
monds). For more detuls see ret. [19| The dashed lines represent our especiation of the DBN1 ielocily The insels shou results of the

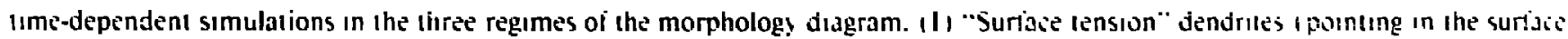

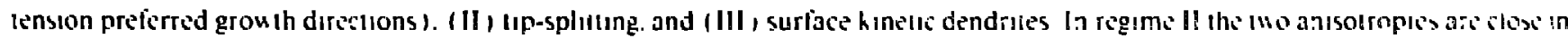

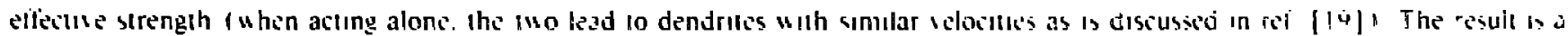

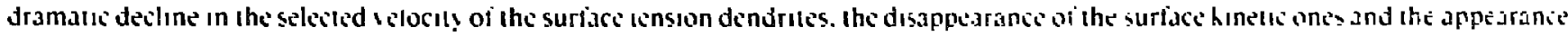

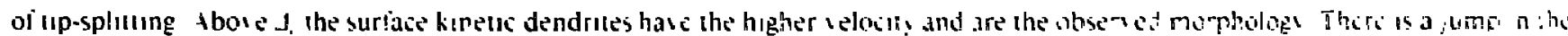

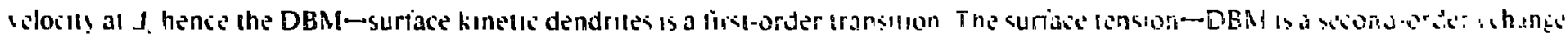

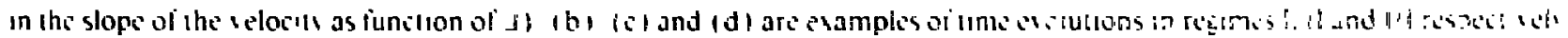

proach lowards global equibrium. In Erow in nrocesses. sfentically . the druing loree lag. the under

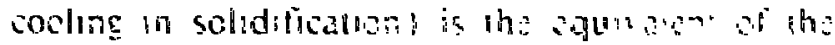
thermodynamic gradient. Thi average velocily measures the rale of anproach inwaruls equilibrum. and series naura!ly as a response funcion. But the global rate of change of the free energ! ia the interface! is guen by the inte, ral of the velocit! along the inte:-

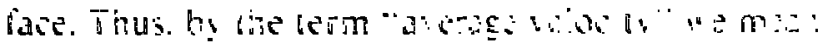

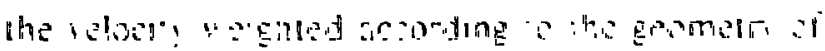

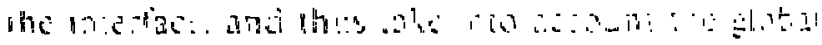

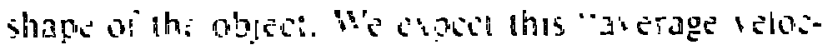
al" lotez imparan variable. tul b! no means the

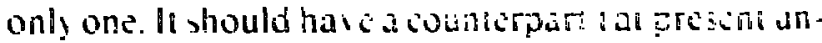
known t hat whl represent the ejultbrium proper-

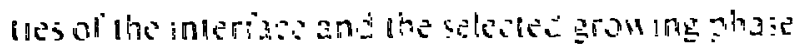


The fastest growing morphology is probably a good approxumation of the general selection principle far enough from equilibrium. where the rate becomes the more dominant part in the competition. It may be $\checkmark$ ieued as a high-temperature limit of an equilibrium system coupled to a heat bath where the entropy dominates. In the same way we expect that far from equilibrium the entropy production is dominant in selecting the morphology.

The analogy with equilibrium systems may be carried even further. We have proposed the existence of two types of morphology transitions [19], as we vary the growth conditions. in analogy to phase transitions in equilibrium. The first kind shows a discontinuous jump in the velocity at the transition point (hence classified as a first order morphology transition ). In the other type (characterized as second order). the velocity itself is continuous as the morphology' changes, hut shows discontinuity in its deri'ative.

In fig. + we show an example of both first-order and second-order morphology transitions found in the BLM. Again we wonder: is this a general phenomenon or an artifact of the BLM? Chan et al. have made a careful study of solidification from supersaturated $\mathrm{NH}_{4} \mathrm{Cl}$ solutions [39]. In particular, their experimental data include information about the velocity of growth which fits well in the framework of morphology transitions described above. They found that. corresponding to changes in crystallographic orientation of the growing dendrites, there was either a jump discontinuity (first order) or a discontinuity in the slope (second order) of the observed dendritic velocity versus supersaturation.

Experiments in growth by electrochemical depositon also produce results in qualitative agreement with the characterization of morphology transitions advanced here. Sawada et al. [27] have plotted the interfacial velocity versus applied voltage and found sudden changes in slope when the morphology changes. In our own experıments of electrochemical

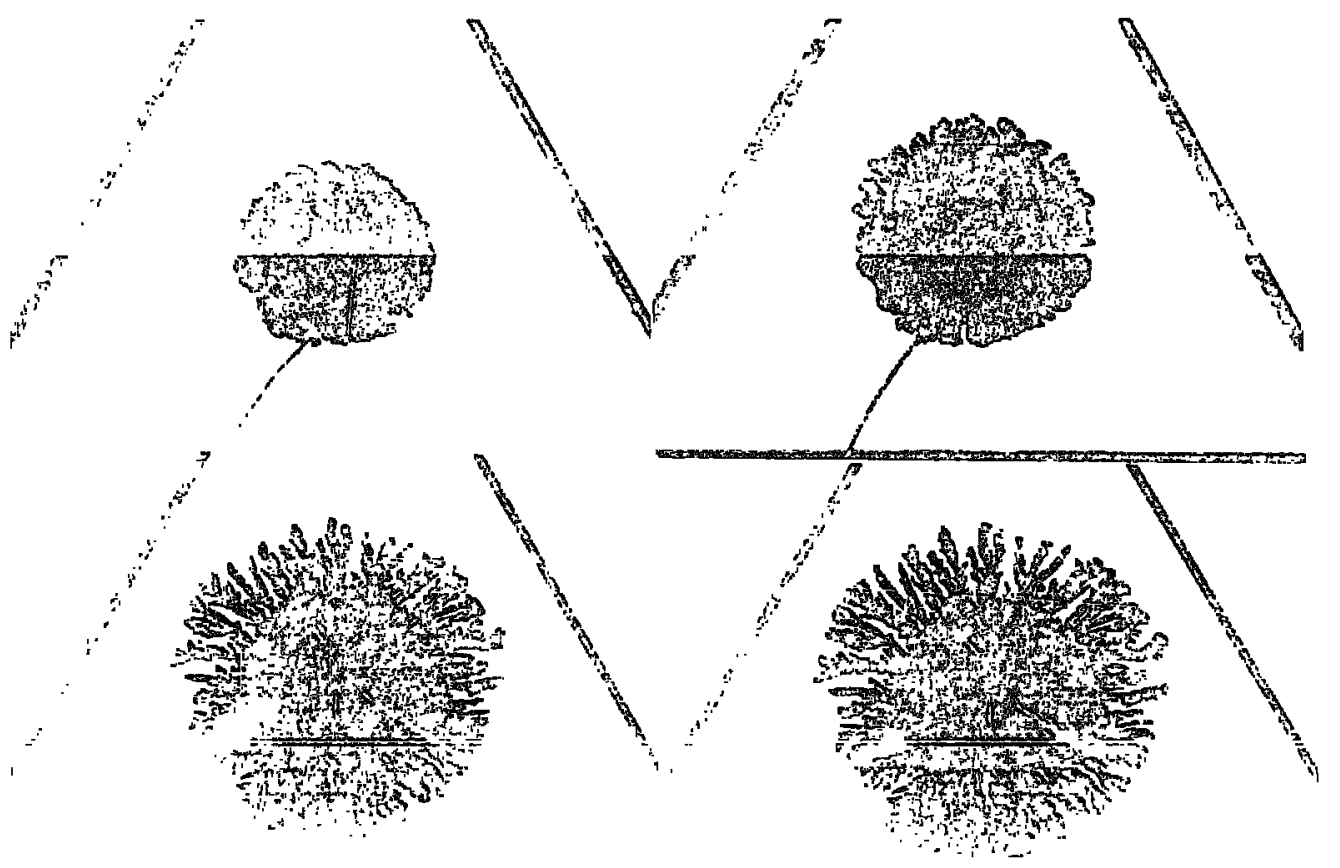

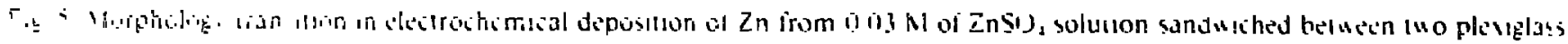

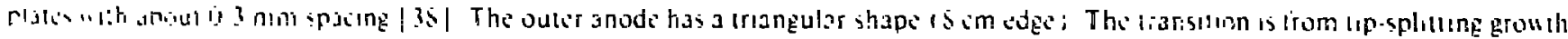

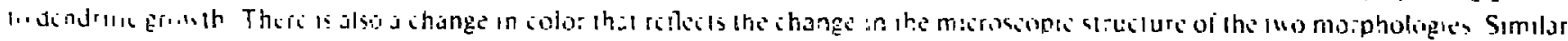

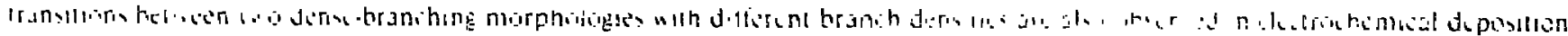

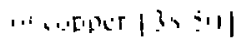


deposition we have observed similar sudden changes in the interfacial velocity with associated morphology transitions [38]. An example of morphology transitions in an electrochemical deposition experiment is shown in fig. 5 . It demonstrates two aspects: the sharpness of the transition and a change in the microstructure of the growing deposit (shown as a color change) corresponding to the morphology change. These observations give additional support to the use of morphology transitions nomenclature.

\section{Conclusion}

The field of nonequilibrium growth has made enormous sirides over the pasi several years. However. many questions remain unanswered. The most pressing is the lack of a theory which can predict morphology selection in diffusion-controlled systems as a function of known cuntrol parameters. More general nonequilibrium princıples also remann to be resolved. with the questlon of the nature of morphodogy transiti- as one of the most interesing.

\section{Achnow ledgemenis}

We are very grateful to Kieran Mullen and Michal Ben-Jacob for their indispensable assistance in preparing and critiquing the manuscript. The research described nere was partially supporied by grants from: the US National Science Foundation. the German! Israel Foundation, and the Donors of the Petruleum Rescarch Fund administered by ihe Amorican Chemical Society

\section{Ratierence:}

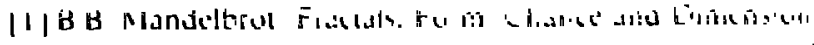

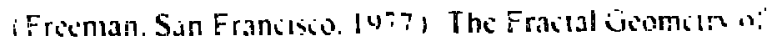
Nalure IFrerman San Francisio. 14sa:

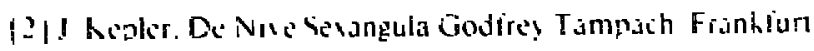
am Misn , ioli

13/9tis) llentworth Thompson on Cirowh and Form

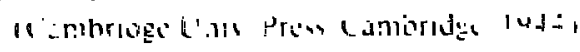

1+|1 S Langer. Re. Mod Phys i2 1/4sul|

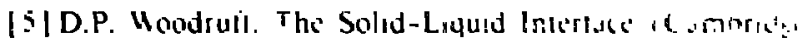
Inis. Piss. Cambrigs. i4'?')

[o] E. Ben-Jacob. G. De stscher. P. Gark. N.D. Goldenfeld and Y. Lareah. Phy's. Reu. Letl 57 (1986) 1903.

[7] T.A. Willen and L M. Sander. Phys Rev. Lell. 47 (1981) I 400. Phys. Res. B 27 (1983) 5686:

P. Meakın. Phỵs. Rev. A 27 1 19831604. 1495

[8| M. Matsushıta. M Sano. Y Hayakawa. H. Honjo and Y Sauada. Phys. Rev. Lell. $53(1484) 286$

|9|L. Pietronero and E. Tosalli. eds. Fractals in Physics (Norh-Holland. Amslerdam. 1985):

J. Nitimann and H E. Stanley. Nature 321 (1036)603.

L.M. Sander. Nalure 322 (1456́) 780.

H E Stanley and N. Osirowshy. ids. Random Fluctuations and Patlem Growih- Experiments and Models I Kilumir Dordrecht. $(985)$.

[10]G.P. I antsou. Dokl. Akad Nauk. SSSR 5811947 ] 567

[11] M.E. Glicksman. R I Shacier and J.D tyers. Metall Trans $+711476,1747$.

S.C Huang and M.E. Gilicksman tida Metall 20,10511 ?(1) 71 :

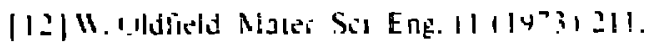

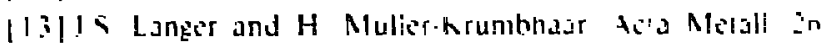

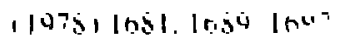

| 1 +

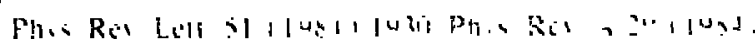
iin

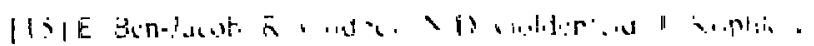

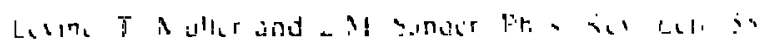

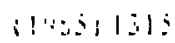

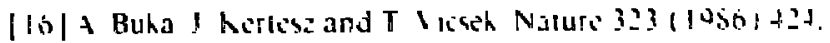
$\checkmark$ Horsath. T I cisch and I Riris:. Phys Res +35 1145712353

I!7|RC Brower D Kessler I Kupls and H Lesine. Pass

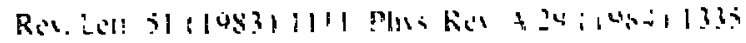

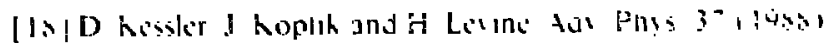
isi

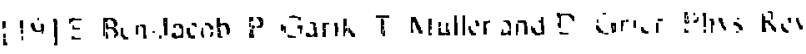
$+3,10, i s: 130$

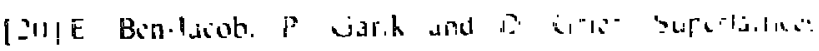

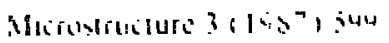

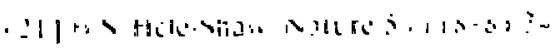

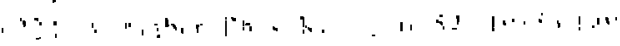

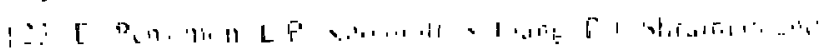

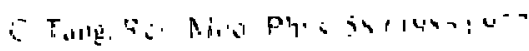

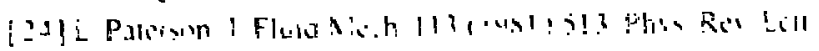

$$
\begin{aligned}
& \text { i: litit) 'n:l }
\end{aligned}
$$

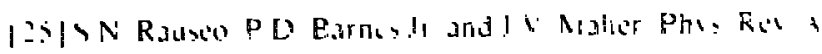

$$
\begin{aligned}
& \text { 31 1457, I } 24
\end{aligned}
$$

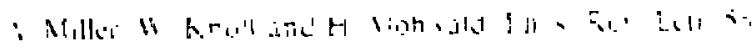

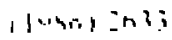


J Nullmann and H E Sianley. Nalure 321 (1086) 66:

I Zn/L i! Sander. P. Ramanlal and E Ben-lacob Phrs Rer. I 3.: (1985) 3160 .

|27| Y Sawada. A. Dougheny and J.P. Gollub. Phys. Rev. Lell. 56 (1986) 1260 .

|28| D. Grier. E. Ben-Jaiob. R. Clarke and L.M. Sander. Phỳ S. Re.. Lell. 56 ( 1986$) 1264$.

[20]E. Raz. E. Polturak and S. Lipson. preprint and privati conımunicalions.

[30|T Fulloka. Ph D. Thesis. Camegie-Mfellon Liniversily $119 ; 31$.

[31] N D. Goldenfeld. J. Crystal Grou th $8+1198716011$.

[32| W W. Mullıns and R.F. Sekerka. J. Appl Phỵs. 34 (19̈63) 323. $35(1964) 4+4$

[33| L. Schwartz. Phys. Fluids 2? (1986) 30̈80

|34|4. Buk a and P Pallị-Muhoras. Phỵs Rev. A 30 1|987 1527 .

$S$ tror: + Buha. P. Palliy-Muhoray and Z. Kacz. preprint

[.5|.1. Niuman. G. Daciord and H.E. Sianley. Nature 314 119851.

G. Daccurd. J. Numman and H E Stanley. Phỵ s. Res. Lett. so l I TSE 336.

G Daciourd and R Lenormand. Nalure 41 (1987)

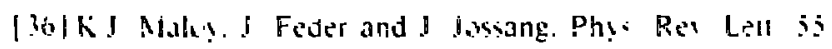
1 1 43512051

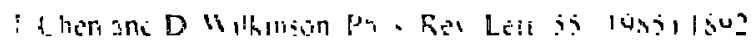

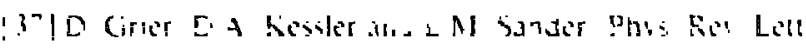
in:

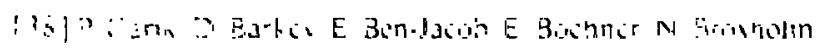
1., MLI: press

f Ju:SK Enan. H H. Reımer and M Kahluel I Cnst Growth

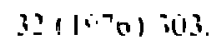

I Hill Enaer. O. Cardoso. D Depus P Tavernier and II. Thom. Europhys. Lelh $2(10$ so 13 ?

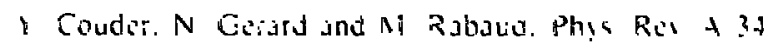
: 10iol \$175.

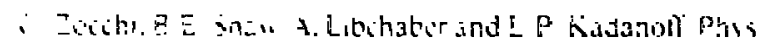
not +3010571501

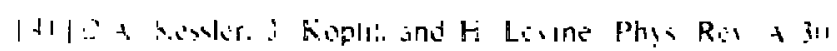
1145, ?1.1
[42|E Ben-Iacob. IN D. Goldenfeld. B.G. Kotliar and I:i Langer. Phys. Res Lell 53 (1093t) 2llo

[43] D. Meiron. Phys. Rev. A 33 ( 1986 ) 2704:

D. Kessler. J. Koplık and H. Levine. Phys. Rev. A 33 (1986) 335::

M1. Ben Amar and B. Moussallam. Physica D 25 (1987) 155.

[44] B.I. Shraıman. Phys. Rev. Lell. 56 (1986) 2028:

D.C. !long and J.S. Langer. Phys. Res. Lell. 56 ( 1986 ) 2032:

Phys. Rev. A 36 (1987) 2325:

R. Combescol. T. Dombre. V. Hakım. Y. Pomeau and A. Pumır. Phys. Rev. Lell. 56 (1986) 2036: Phys. Rev. A 37 (1988) 1270:

S Tanveer. Phys. Fluids 30 (1987) 1589.

A.T. Dorsey and O. Martın. Phys. Rev. A 35 ( 1987 ) 3989:

P Pelce and + Pumır. J. Cryst. Gisu lh 73 , 1985 , 337.

|45| A Barbien. D.C. Hong and J.S. L.anger. Phys. Rev. A 35 (1984) 1802.

G.A. Brener. S.V. Iordanskii and V.I. Melnikor. JETP 9 , 19881.

M Kruskal and H. Segur. Aeronautical Research Associates of Princicion. Technical Miemo. s.5-3: 1 19851. unpublıshed:

B Caroh. C Carolı. B. Roulet and I.S. Langer. Phy s. Res. +331198ins t+2.

P Pelicand I Fomeau. Siud Appl. M.lath 7\$ 1 19661245.

$|2 n|\rangle$ Sallo $G$ Goldbech-lheod and $H$. Muller-hrumbhar. Phys Rev. Lel! 58, 1957।15HI

$\left|f^{\top}\right|+$ Doughens. P.D. Kaplan and I P Gollub ian s. Rer Lell $\therefore$, $1: 37: 0$ :

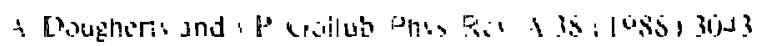

|48| R. Pieters and J S. Langer. Phus. Ret. Leil. 56 ( 1987) 1948: M. Barber. A. Barbien and J.S. Langer. Phys. Res. A só

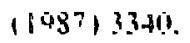

D 4. Kessler and H. Leune. Phys. Rev A $36119871+123$. Q Marin and N. Goldenteld. Phys. Rev. A 35 (1987) 138.

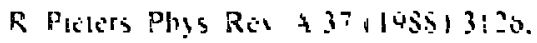

15 Langer. Phys. Ra A 3019957,3550

D. 7 . Kessler and H. Lewne. Ph!s Rer $+33,105612621$. 2631

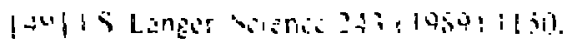

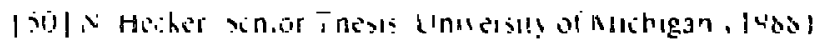

